http://dx.doi.org/10.4314/bajopas.v12i1.3S

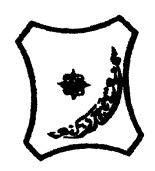

Bayero Journal of Pure and Applied Sciences, 12(1): 13 - 17

ISSN $2006-6996$

\title{
ANTIBACTERIAL ACTIVITY OF LOCAL HONEY AGAINST CARBAPENEM RESISTANT ENTEROBACTERIACEAE ISOLATED FROM INFECTED WOUNDS
}

\author{
*Aminu, B.M. and Khadija, M.L. \\ Department of Microbiology, Bayero University, P.M.B. 3011, Kano, Nigeria. \\ *Correspondence author email:bintaaminu78@yahoo.com, 08029169999.
}

ABSTRACT

The increasing incidence of drug resistant organisms such as Carbapenem Resistant Enterobacteriaceae (CRE) has resulted in difficulties in the management of infected wound. Integration of traditional medicine such as honey and modern antibiotics could be useful in the treatment of such infections. This research work is therefore aimed at evaluating the antibacterial activity of local honey against CRE isolated from infected wounds. Four hundred wound swabs (surgical, burn, diabetic foot ulcer, osteomylitis, abscess and laceration wound swab) obtained from Murtala Muhammad Specialist hospital and Muhammad Abdullahi Wase hospital Kano were screen for the presence of CRE. The isolates were identified and confirmed using culture, biochemical and meropenem sensitivity test according to standard microbiological techniques. The antibacterial activity and MIC of the honey was evaluated using agar well diffusion and tube dilution method respectively. A total of 253 organisms of the family Enterobacteriaceae from 342 samples that yielded growth were identified. The isolates were Escherichia coli 54 (21.3\%), Klebsiella species 92 (36.4\%), Proteus species 36 (14.2\%), Pseudomonas species 54 (21.3\%) and Enterobacter species 17 (6.7\%). The study revealed the incidence of CRE as $8.46 \%$. The result of antibacterial activity of honey revealed activity at all concentration (12.5\% to $100 \%)$ with the diameter of inhibition ranging from $10 \mathrm{~mm}$ to $38 \mathrm{~mm}$. The result also revealed that $81.8 \%$ isolated CRE were sensitive to the local honey with varied bacteriostatic activity. The MIC values of the honey were found in the range of 12.5- $50 \%(\mathrm{~V} / \mathrm{V})$. The antibacterial activity of honey even at lower strength justify their efficacy in the treatment of wound infection. Honey can therefore serve as potential antimicrobial substance for control of wound infection caused by CRE.

Key words: Activity, Honey, Wound, CRE, Agar-well diffusion.

\section{INTRODUCTION}

A variety of plants and their extracts are used in the traditional medicine for treatment of various infections worldwide. This practice has continued to be a main source of healthcare in many communities. One of the natural antimicrobial substances described in the ancient medicine is honey (Mandal and Mandal, 2011). The use of honey to treat infected wounds dates to many centuries ago before the discovery of various types of bacteria that causes wound infection (Nura et al., 2012).

Honey is the natural sweet substance from nectar or bosoms or from the secretion of living parts of plants or excretions of plants, which honey bees (Apis mellifera) collect, transform and store (Khandal et al., 2010). Though honey is used widely in traditional medicine throughout the world its use in modern medicine is limited due to lack of scientific supports (Nura et al., 2012). Several studies revealed the antibacterial activity of honey against both Gram negative and Gram positive bacteria (Khadija et al., 2018; Al-Wali et al., 2005). It is also used effectively as wound dressing including surgical wound, burns and skin ulcers because it speeds up the growth of new tissues, help to heal the wound and reduce pain and odor quickly (Lusby et al., 2002).

Enterobacteriaceae is a heterogenous family of Gram negative, non spore forming, and facultative anaerobic rods. They cause variety of infection including urinary tract, wound and gastrointestinal infections (Ghotaslou et al., 2018). 
Carbapenem resistant Enterobacteriaceae (CRE) are strains of bacteria that are resistant to carbapenem, an antibiotic considered as last resort for the treatment of infection due to multidrug resistant Enterobacteriaceae. CRE are also resistant to $\beta$-lactam, aminoglycosides and floroquinolones agents: CRE is a threat to public health being a major cause of therapeutic failure in both hospital and community infection (Ghotaslou et al., 2018).

The increasing incidence of CRE has resulted in difficulties in the management of infected wound. Integration of traditional medicine such as honey and modern medicine could be useful in the treatment of wound infection. This study is therefore aimed at evaluating the antibacterial activity of local honey and compared with the commonly prescribed imported honey against CRE isolated from different infected wound.

\section{MATERIALS AND METHODS}

\section{Specimen Collection (Wound Swab)}

Ethical permission for the study was obtained from hospital management board Kano State. Wound swabs were collected from consented patients with infected wounds attending Murtala Muhammad Specialist Hospital and Muhammad Abdullahi Wase Specialist Hospital, Kano from September 2017 to May 2018. A sterile swab stick was used to collect cells or pus from superficial wound while a syringe was used for deeper wounds aspirates according to Cheesbrough (2010).

Isolation and Identification of Test Isolates (CRE)

All media used were prepared according to manufacturers protocols. Wounds swabs collected were inoculated directly on to blood and MacConkey agar medium and incubated at $37^{\circ} \mathrm{C}$ over night. Plates that yield growth were examined for colonial morphology. Isolates were Gram stained and observe microscopically. Gram negative rod isolates were subjected to different biochemical test including oxidase, krigler iron Agar, Triple sugar iron agar, voges proskauer, citrate utilization, urease production, indole production and motility test according to the procedure of Arora and Arora (2016).

Susceptibility to carbapenem antibiotics was performed using the disc diffusion method according to CLSI (2017) guidelines. Bacterial colonies were suspended in sterile normal saline to match the turbidity of 0.5 McFarland standards. Muller - Hinton agar was inoculated with the standardized inoculums aseptically. A $10 \mu \mathrm{g}$ meropenem disk was placed in the centre. The plates were then incubated at $37^{\circ} \mathrm{C}$ overnight. Zone of inhibition was measured and the reading was compared with CLSI (2017). Diameter of inhibition of $\geq 16 \mathrm{~mm}$ is considered sensitive and $\leq 13 \mathrm{~mm}$ as resistant.

\section{Honey Samples}

Honey samples (Local and imported) were collected, labeled and stored in sterile screwed cup container in a cool and dry place. The samples were filtered with a sterile mesh to remove the debris and diluted with physiological saline to yield $12.5,25,50,75 \%$ and non diluted honey $(100 \%)$ according to the procedure of Chauhan et al. (2010).

\section{Sensitivity Assay}

Three colonies were picked from CRE culture plates using sterile wire loop and suspended in $4 \mathrm{mls}$ nutrients broth. The mixture was incubated at $37^{\circ} \mathrm{C}$ for 24 hours. The bacterial suspension was adjusted to turbidity matching 0.5 McFarland standards using normal saline (Wasihun and Kasa, 2016).

Antibacterial activities of all the honey samples were evaluated using Agar well diffusion method (Wasihun and Kasa, 2016). One hundred microlitre of the adjusted culture of each of the isolate was mixed in $100 \mathrm{ml}$ of sterile molten Mueller - Hinton Agar, mixed and dispensed in sterile petridish. The plates were allowed to solidify and four wells of $6 \mathrm{~mm}$ diameter was punched on each plate using sterile cork borer one hundred microlitre of each of the honey concentrations and the control were placed into the well. Plates were incubated at $37^{\circ} \mathrm{C}$ for 24hours. The antibacterial activity was assessed by measuring the diameter of the zone of inhibition using vernier caliper.

\section{Determination of Minimum Inhibitory Concentration (MIC)}

The minimum inhibitory concentration of the active honey was determined using broth tube dilution method as described by Kacaniova et al. (2011). Ten sterile tubes were arranged and labeled in rack ( 8 for test and 2 controls). One milliliter of freshly prepared sterile nutrient broth was added to each tube and allowed to cool. One milliliter of undiluted honey sample $(100 \%)$ was added to test tube number 1 and honey control tube using sterile micropipette. The mixtures were homogenized by votexing. The samples were serially diluted using two fold serial dilution through the 8 tubes thereby decreasing the concentration. The control tubes are honey control tube and growth control tube. The growth control tube received no honey while the honey control tube received no bacterial inoculum. 
Each of the test tube and growth control tube were inoculated with $0.1 \mathrm{ml}$ of the culture of the respected organisms and incubated at $37^{\circ} \mathrm{C}$ for 24 hours. The tubes were then observed for the presence and absence of turbidity (growth).

\section{RESULTS}

A total of 253 (74\%) Enterobacteriaceae isolates including 54 (21.3\%) E. coli, $92(36.4 \%)$ Klebsiella species $36(14.2 \%)$ Proteus species 54 (21.3\%) Pseudomonas species and 17 (6.7\%) enterobacter species were isolated from different wound infection (Table 1). Carbapenem (meropenem) susceptibility showed that $119(91.54 \%)$ of the 130 isolates screened were meropenem sensitive and $11(8.46 \%)$ were meropenem resistant (Table 2). Pseudomonas species were found to be the most resistant isolates (Table 2).
The result of the antibacterial activity of local and imported honey revealed activity at both concentrations $(12.5,25,50,75$ and $100 \% \mathrm{~V} / \mathrm{V})$ against $E$. coli and Klebsiella $s p$. and only active against Pseudomonas $s p$. at higher concentrations. No significant difference was found in the diameter of inhibition of local and imported honey $(P=0.0001)$ at $5 \%$ level of significance while the activity of honey was significantly higher than that of ciprofloxacin (Table 3 )

The MIC of the both local and imported honeys ranged between 12 to $50 \% \mathrm{v} / \mathrm{v}$ against the CRE isolates (Table 4).

The susceptibility profile of the isolated CRE to the honeys revealed that all the isolates were sensitive to the honey samples except Pseudomonas $s p$. in which $2(50 \%)$ of the tested isolated were resistant to both imported and local honeys (Table 5).

Table 1: Frequency of Occurrence of Enterobacteriaceae Isolated from Different Wounds

\begin{tabular}{|c|c|c|c|c|c|c|c|}
\hline Wound & $\begin{array}{l}\text { Number } \\
\text { examined }\end{array}$ & Escherichia coli & Klebsiella sp & Proteus sp & Pseudomonas sp & Enterobactersp & Total \\
\hline Surgical wound & 193 & 34 & 29 & 29 & 20 & 10 & 122 \\
\hline Burn & 87 & 07 & 46 & 04 & 20 & 03 & 80 \\
\hline Diabetic foot ulcer & 28 & 08 & 14 & 03 & 11 & 04 & 40 \\
\hline Osxteomyellitis & 06 & 00 & 03 & 0 & 02 & 00 & 05 \\
\hline Abscess & 19 & 00 & 00 & 0 & 00 & 00 & 00 \\
\hline Laceration & 09 & 05 & 00 & 0 & 01 & 00 & 06 \\
\hline Total & 342 & $54(21.3 \%)$ & $92(36.4 \%)$ & $36(14.2 \%)$ & $54(21.3 \%)$ & $17(6.7 \%)$ & 253 \\
\hline
\end{tabular}

Table 2: Susceptibility of Isolated Enterobacteriaceae to Carbapenem (Meropenem)

$$
\text { Isolated Susceptibility to Carbapenem (Meropenem) } \mathbf{n}=130
$$

\section{Enterobacteriaceae}

\begin{tabular}{llll} 
& Number sensitive & Number resistant & Total \\
\hline Escherichia Coli & $27(90)$ & $3(10)$ & 30 \\
Klesiella sp. & $36(90)$ & $4(10)$ & 40 \\
Proteus sp & $20(100)$ & $0(0)$ & 20 \\
Pseudomonas sp & $23(85)$ & $4(15)$ & 27 \\
Enterobactersp & $13(100)$ & $0(0)$ & 13 \\
Total & $\mathbf{1 1 9 ( 9 1 . 5 4 \% )}$ & $\mathbf{1 1}(\mathbf{8 . 4 6 \% )}$ & $\mathbf{1 3 0}$ \\
\hline
\end{tabular}


Table 3: Antibacterial Activity of Honey Showing Diameter of Inhibition (MM) against CRE (Mean Diameter \pm SD)

\begin{tabular}{llll}
\hline $\begin{array}{l}\text { Honey } \\
\text { Local v/v Conc. \% }\end{array}$ & E. coli & $\begin{array}{c}\text { ISOLATES } \\
\text { Klebsiella sp. }\end{array}$ & Pseudomonas sp. \\
\hline 12.5 & $16 \pm 1.2$ & $11 \pm 2.3$ & 0.00 \\
25 & $20 \pm 2.8$ & $16 \pm 2.1$ & 0.00 \\
50 & $22 \pm 1.9$ & $22 \pm 2.5$ & $16 \pm 3.2$ \\
75 & $25 \pm 2.3$ & $23 \pm 2.2$ & $18 \pm 1.3$ \\
100 & $25 \pm 3.8$ & $22 \pm 3.1$ & $19 \pm 1.5$ \\
Imported v/v \% & & & \\
12.5 & $16 \pm 1.5$ & $10 \pm 2.8$ & 0.00 \\
25 & $18 \pm 2.7$ & $17 \pm 3.1$ & 0.00 \\
50 & $21 \pm 1.6$ & $23 \pm 2.5$ & $15 \pm 1.8$ \\
75 & $24 \pm 2.1$ & $24 \pm 1.9$ & $16 \pm 2.1$ \\
100 & $25 \pm 2.1$ & $24 \pm 2.1$ & $20 \pm 4.1$ \\
Ciprofloxacin $5 \mu \mathrm{g} / \mathrm{ml}$ & $16 \pm 2.1$ & $14 \pm 2.1$ & $10 \pm 1.8$ \\
\hline
\end{tabular}

Table 4: Minimum Inhibitory Concentration of Honey against CRE (\% v/v)

\begin{tabular}{lll}
\hline Isolates & Local Honey & Imported \\
\hline E. coli & 12.5 & 12.5 \\
Klebsiella sp. & 12.5 & 12.5 \\
Pseudomonas sp. & 50 & 50 \\
\hline $\mathbf{P}>\mathbf{0 . 0 5}$ & &
\end{tabular}

$\mathbf{P}>0.05$

Table 5: Summary of the Antibacterial Activity of Honey against CRE

\begin{tabular}{llllll}
\hline Isolates & $\begin{array}{l}\text { Number } \\
\text { Tested }\end{array}$ & $\begin{array}{l}\text { Local Honey } \\
\text { Number }\end{array}$ & $\begin{array}{l}\text { Number } \\
\text { resistant }\end{array}$ & $\begin{array}{l}\text { Number } \\
\text { sensitive }\end{array}$ & $\begin{array}{l}\text { Number } \\
\text { resistant }\end{array}$ \\
\hline E. coli & 3 & $3(100 \%)$ & $0(0 \%)$ & $3(100)$ & $0(0)$ \\
Klebsiella sp. & 4 & $4(100 \%)$ & $0(0 \%)$ & $4(100)$ & $0(0)$ \\
Pseudomonas sp & 4 & $2(50 \%)$ & $2(50 \%)$ & $2(50 \%)$ & $2(50 \%)$ \\
\hline
\end{tabular}

\section{DISCUSSION}

The findings of this study revealed Klebsiella sp. as the most predominant enterobacteriaceae isolated. This contradict the previous report of Mohammed (2013) and Dahab et al. (2017) in which Pseudomonas sp. and Proteus mirabilis were found to be the most predominant isolates from wound respectively.

Resistance to meropenem (carbapenem) antibiotics was found to be $8.5 \%$. This value is lower than $13 \%$ obtained by Dahab et al. (2017) and $25.4 \%$, by Mohammed (2013) in Khartoum. Detection of CRE from wound could be serious threats in the management of patient with wound infection. Carbapenem is the last resort antibiotic for treating infections caused by multidrug resistant Enterobacteriaceae (Dahab et al., 2017). The most resistant isolates in this study were Pseudomonas sp (15\%). This is in line with Dahab et al. (2017) findings. Other study by Yusuf et al. (2012) in Kano revealed $E$. coli as the most resistant isolates.

The result of this study revealed excellent in vitro activity of honey against CRE isolates ( $E$. coli and Klebsiella $\mathrm{sp}$ ) and some strains of Pseudomonas sp. This is in line with the report of Wasihun and Kasa (2016), who also reported excellent activity of honey against multidrug resistant bacteria in Ethiopia. The antibacterial activity of the honey might be attributed to its high osmotic effect, high acidic nature, hydrogen peroxide concentration and its phytochemical contents (Khandal et al., 2010). The diameters of inhibition of the honeys were significantly higher than that of control drug ciprofloxacin. This could be due to the fact that CRE are resistance to wide range of antibiotics including $\beta$-lactam agents, aminoglycoside and fluroquinolones (Ghotaslou et al., 2018).

Some strains of Pseudomonas $s p$. were found to be resistant and others were relatively inhibited at higher concentrations. Similar studies by Efem (1988), reported resistance to honey by Pseodomonas aeruginosa. Wasihu and Kasa (2016) reported activity of honey against Pseudomonas sp. at higher concentrations than other bacteria. Resistance to honey by Pseudomonas sp could be due to the low permeability of its cell wall, genetic capacity to express resistant mechanisms and mutation in chromosomal genes which regulate resistant genes (Wasihun and Kasa, 2016). 
Special Conference Edition, November, 2019

The minimum inhibitory concentration of honeys against $E$. coli and Klebsiella sp. (12.5\% v/v) and $50 \% \mathrm{v} / \mathrm{v}$ for Pseudomonas $\mathrm{sp}$. is comparable to the work of Wasihun and Kasa (2016) which revealed MIC in the range of 6.25 - $12.5 \% \mathrm{v} / \mathrm{v}$ against $E$. coli and Proteus mirabilis and 12.5 - 50\% v/v against Pseudomonas aeruginosa. Study by Ahmed et al. (2014) revealed lower MIC of $6.5 \% \mathrm{v} / \mathrm{v}$ of honey against E. coli and Proteus mirabilis and $7.5 \%$ $\mathrm{v} / \mathrm{v}$ against Pseodomonas aeruginosa.

\section{REFERENCES}

Ahmed, M. Sahile, S.and Subramanian (2014): Evaluation of Antibacterial Potential of Honey against some common human pathogens in North Gonder Zone of Ethiopia. International Journal of Pure and Applied Zoology 2(4): 268 - 295.

Al-wali, N. Akmal, M., Al-wali, F., Saloom, K. and Ali, A., (2005). The Antimicrobial Potential of Honey from United Arab Emirates on some Microbial Isolate. Medical Science Monitoring 11: 433 - 438.

Arora, B. and Arora, D.R. (2016): Practical Microbiology CBS Publishers New delhi India. P: $40-45$.

Chauhan, A., Pandey, V., Chacko, K.M. and Khandal, R.K. (2010). Antibacterial Activity of raw and Processed Honey. Electronic Journal of Biology 5(3): $58-66$.

Cheesbrough, M. (2010): District Laboratory Practice in Tropical Countries U.K. Cambridge University Press. 283 - 285.

Clinical and Laboratory Standards Institute, (CLSI) (2017). Performance Standards for Antimicrobial Susceptibility Testing $27^{\text {th }}$ Edition CLSI Supplement.

Dahab, K.R., Ibrahim, AM. And Mohammed M.B. (2018). Detection of Cabapenem Resistant Gram - Negative Bacilli from Infected Wounds in Khartoum State: Journal of Clinical Microbiology 6(4): $1-4$.

Efem, F. (1988): Clinical observation on the Wound Healing Properties of Honey. British Journal of Surgery 57: $679-681$.

Ghotaslou, R., Alizaden, N. Mohammad, A.R., Kafel, H.S. Mohammad, H.S. and Alka H. (2018). Detection of Carbapenem Resistant Enterobacteriaceae by Chromogenic Screening Media. Journal of Microbiological Methods 153: 40 - 44.

Kacaniova, M. Vukovic, N. Bobkova, A., Filselova, M. Rovna, K., and Wascik, P. (2011): Antimicrobial and Antiradical Activity of Slovakian Honeydew Honey sample.

\section{CONCLUSION}

The study revealed higher incidence of CRE $(8.56 \%)$ in wound infection, which indicate increase in drug resistance and therefore cannot be neglected. The study also revealed excellent activity of local honey similar to imported honeys against CRE isolated from different wound infection. The local honey should therefore be recommended in wound dressing as an alternative to imported honeys which are more costly and less available. The antibacterial activity of honey even at lower strength justifies its usefulness as potential agent against wound infection especially those associated with carbapenem resistant Enterobacteriacea.

Journal of Microbioalogy Biotechnology and Food Science 1(3): $354-360$.

Khadija, M.L., Binta, M.A. and Abdulrazak M.H. (2018). Antibacterial Activity of Local Honey Against Methicillin Resistant Sphylococcus aureus (MRSA) Isolated from wound Infection Bayero Journal of Medical laboratory Science 3(1): 294 - 301.

Khandal, K. Abhishek, C., Pandey, V. and Chacko, K.M. (2010): Antibacterial Activity of Raw and Processed Honey. Electronic Journal of Biology 5(3): $58-66$.

Lusby, P.E., Coombe, A., Wilkinson, J.M. (2002): Honey a Potent Agent for Wound Healing. Journal of Wound Ostomy Control Nursing 29: $295-300$.

Mandal, M.D. and Mandal, S. (2011). Honey Medicinal Property and Antibacterial Activity Asian Pac Journal of Tropical Biomedical 1(2): 154 - 160.

Mohammed, R., (2013): Phenotypic Detection of New Delhi Metallo - beta Lactamases Producing Gram - Negative Bacilli causing Pyogenic Infections in Khartoum State. University of Medical Sciences of Technology, Faculty of Medical Laboratory Science.

Nura, S., Tijjani, A., Mohammed, A.S., Salisu, S.S. and Ahmed, A. (2012): Antibacterial Potentials of Honey (A review), European Journal of Scientific Research 93(1), 54 61.

Wasihun, A.G. and Kasa, G.B. (2016): Evaluation of Antibacterial activity of Honey against Multidrug Resistant Bacteria in Ayder Referral and Teaching Hospital, Northern Ethiopia Springer Plus 5: 842: $1-8$.

Yusuf, I., Yusha'u, M. Sharif, A.A. Getso, M.J. and Yahaya, H. (2012). Detection of metalobeta - lactamase among Gram - Negative Bacterial Isolates from Murtala Muhammad Specialist Hospital, Kano and Almadina Hospital, Nigeria. Bayero Journal of Pure and Applied Science 5: 84 - 88. 